\title{
The Antibacterial Effect of Aqueous Extract of Garlic against Resistant Enterococci
}

\author{
Shaghayegh Nikpour Moghadam(MSc) \\ Department of Microbiology, Islamic Azad \\ University of Tonekabon, Tonekabon, Iran \\ Shokoufeh Nikpour Moghadam(MSc) \\ Department of Cellular and Molecular \\ Biology-Biochemistry, Islamic Azad \\ University of Falavarjan, Isfahan, Iran \\ Corresponding Author: Shaghayegh \\ Nikpour \\ Email: sh.nikpour@yahoo.com \\ Tel: +989112574867
}

Address: Department of Microbiology, Islamic Azad University of Tonekabon, Tonekabon, Iran

Received : 04 Feb 2014

Final edit: 17 Jan 2015

Accepted: 24 Jsn 2015

\section{ABSTRACT}

Background and Objective: Enterococci are relatively nonvirulent bacteria that rarely cause disease. Antimicrobial treatment of Enterococci is often challenging due to their antibiotic resistance. This study aimed to investigate the antibacterial activity of aqueous extract of garlic against Enterococcal isolates.

Methods: In this descriptive study, 120 Enterococcus isolates including 70 multidrugresistant isolates were collected from hospitals of Babol, Iran. Isolates' susceptibility to different antibiotics and the antibacterial activity of garlic extract were assessed using methods of minimum inhibitory concentration (MIC) measurement. The experiments were performed according to the Clinical \& Laboratory Standards Institute guidelines, using Tryptic soy broth medium and disc diffusion method.

Results: Among the 120 Enterococcal isolates, 95 (79.2\%) and 25 isolates (20.8\%) were E. faecalis and E. faecium, respectively. of the all Enterococcal isolates, the highest resistance was to erythromycin (95.8\%), tetracycline (80.3\%) and ampicillin (65.8\%). While, the minimal level of resistance was to chloramphenicol (6.8\%), vancomycin (20\%) and ciprofloxacin (25\%). Also, 53.3\% of Enterococcal isolates showed simultaneous resistance to at least three antibiotics (tetracycline, erythromycin and ampicillin). Such resistance in E. faecium isolates was higher compared to E.faecalis (60\% vs. 55.7\%). The range of antibacterial activity of garlic extract against isolated Enterococci was determined by growth inhibition zone of $16.8 \pm 1.8 \mathrm{~mm}$ and IIC of between 4 to $32 \mathrm{mg} / \mathrm{ml}$.

Conclusion: This study indicates the clear anti-enterococcal effect of aqueous extract of garlic and confirms the use of garlic in treatments by medicinal plants.

Keywords: garlic extract, multi-drug resistance, minimum inhibitory concentration, Enterococcus 


\section{INTRODUCTION}

Garlic (Allium sativum) is a plant from the Liliaceae family, which is endemic in central Asia and can be found today in all parts of the world. From centuries ago, different species of this plant were used as a spice and food additive in cooking, and also applied as a drug in herbal medicine for treatment of various types of diseases (1). Garlic has antibiotic, anti-cancer, antioxidant, anti-inflammatory, hypoglycemic and cardioprotective properties (2). The antibacterial effects of garlic on different bacteria types has been reported $(3,6)$. Enterococci are commensal gut bacteria and as opportunistic pathogens, are capable of causing urogenital tract infections, endocarditis, meningitis, intra-abdominal abscesses, bacteremia, neonatal sepsis and nosocomial infections (5). Almost 20 species are in the genus Enterococcus, two of which (E.faecalis and E.feacium) are responsible for almost $90 \%$ of all Enterococcal infections in humans (5). The pathogenicity of Enterococci is affected by resistance to various antibiotics, rather than its virulence factors. Selective pressure caused by antibiotic overuse during the past 50 years on one hand, and the capacity of Enterococci to acquire and disseminate antibiotic resistance determinants on the other, are some of the risk factors that highlight the need for continuous monitoring of antibiotic resistance in these bacteria. Multiple antibiotic resistance development increase healthcare costs and leads to relapse of previously controlled diseases. This in turn increases the incidents of opportunistic and chronic infections in the world (6). Patients often prefer medicinal plants due to their lower costs and fewer unwanted side effects compared to chemical drugs (7). Given the above facts, antibacterial effects of garlic and abundance of its cultivation and its either raw or processed consumption in Iran, this study aimed to investigate the antibacterial properties of garlic aqueous extract against various multidrug-resistant (MDR) Enterococci in city of Babol. Studying the range of antibacterial properties of garlic against the isolated strains may confirm the potential role of this plant in treatment of microbial infections.

\section{MATERIAL AND METHODS}

The Bakri and Douglas methods were used in this descriptive study to prepare the aqueous extract of garlic. First, 80 grams of garlic were peeled after weighing and washing, then crushed and thoroughly mixed and homogenized by an electric mill in 100 $\mathrm{ml}$ of sterile distilled-water. The mixture was centrifuged for $20 \mathrm{~min}$ at $6000 \mathrm{rpm}$. The resulting supernatant was passed through the Whatman (Grade 1) filter and then became sterile by passing through a $0.45 \mu$ filter (Millipore). The final concentration of the garlic extract was estimated as $512 \mathrm{mg} / \mathrm{ml}$, after subtracting the weight of the insolubles from the weight of raw garlic cloves (8). The Enterococcal isolates used in this study were obtained from patients with bacteremia, pneumonia and urinary tract infections. Isolates' identity was confirmed by colony morphology and Gram staining, while their biochemical properties were assessed using esculin hydrolysis in the presence of bile, growth in the presence of $\mathrm{NaCl} 5.6 \%$ and Pyrrolidonyl Arylamidase test. Carbohydrate fermentation tests (arabinose, mannitol, sorbitol, sorbose and lactose) were used to determine the species (9). Antibiotic susceptibility of Enterococcus isolates was assessed by disk diffusion test using erythromycin ( $\mu \mathrm{g} 15)$, tetracycline ( $\mu \mathrm{g} 30)$, ampicillin ( $\mu \mathrm{g} 10)$, gentamicin ( $\mu \mathrm{g} 10)$, ciprofloxacin ( $\mu \mathrm{g} 5)$, vancomycin ( $\mu \mathrm{g} 30)$ and chloramphenicol ( $\mu$ g 15) (MAST Co., UK). High level of gentamicin resistance test was done using $120 \mathrm{mg}$ gentamicin disks. In order to assess the Enterococcus strains' susceptibility to garlic extract, a suspension of Enterococcal isolates with turbidity equivalent to 0.5 McFarland units was prepared in Mueller Hinton Broth. Then, 0.1 $\mathrm{ml}$ of the suspension was cultured on Mueller Hinton agar medium and sterile blank disk were soaked in the garlic extract by Whatman filter paper No.1 (Padtan Teb Co.) with a diameter of $5 \mathrm{~mm}$. After 5 minutes of drying at $60{ }^{\circ} \mathrm{C}$, the disks were placed on the plate's surface. Blank discs soaked in distilled water were used as negative controls. After 24 hours of incubation at $37{ }^{\circ} \mathrm{C}$, the diameter of inhibition zone around the discs were measured in millimeters. The minimal inhibitory concentration (MIC) was determined by microdilution in wells using Tryptic soy broth. A suspension was prepared from the 24-hour culture of bacteria with final concentration of $1.5 \times 10^{6} \mathrm{CFU} / \mathrm{ml}$, which 
was later diluted $1 / 100$ by Mueller Hinton broth. Stock vancomycin antibiotics with concentration of $10 \mathrm{mg} / \mathrm{ml}$ was obtained using pure vancomycin powder (SERVA Co.) and antibiotic dilutions of 1536, 768, 384, $192,96,48,24,12,6,3,1.5$ and $0.75 \mu \mathrm{g} / \mathrm{ml}$ were prepared. In this method, bacterial suspension with $1 / 100$ dilution along with the prepared concentrations of antibiotics was added to the microplates. After incubation at $37{ }^{\circ} \mathrm{C}$ for 24 hours, MIC of strains was determined by considering the lowest concentration of antibiotics at which no growth was observed. E. faecalis ATCC 29212 (susceptible) and E.faecium BM 4147 (resistant) strains were used as positive and negative controls, respectively. Obtained results were interpreted according to guidelines of the National Committee for Clinical Laboratory Standards (10). Data were analyzed using SPSS-14 software.

\section{RESULTS}

In this study, 120 clinical isolates of Enterococci were investigated including 47 urine samples $(39.1 \%), 34$ blood samples (28.3\%), 21 skin and soft tissue samples $(17.5 \%)$ and 15 samples from the respiratory tract (18\%). Of the 120 Enterococcal isolates, 24 isolates (20\%) were vancomycin-resistant (through microdilution) (MIC $>8 \mu \mathrm{g}$ ) and grew well around the vancomycin disc. Of the $95 E$. faecalis isolates, five isolates were vancomycin-resistant (5.2\% of this specie and $4.2 \%$ of all isolates), and out of 25 E. faecium strains, 19 were resistant to this antibiotics (76 $\%$ of all isolates of this species and $15.8 \%$ of all isolates) (Table 1). The results of the antibiogram test and MIC determination are presented in Table 2. The investigated Enterococci showed the highest level of resistance against erythromycin (95.8\%), tetracycline $(88.3 \%)$ and ampicillin $(65.8 \%)$, while showing minimal resistance against chloramphenicol (6.8\%), vancomycin (20\%) and ciprofloxacin (25\%). Also, $53.3 \%$ of all the Enterococcal isolates showed simultaneous resistance against at least three antibiotics (tetracycline, erythromycin and ampicillin). This type of resistance was observed more in the E. faecalis $(68 \%)$ isolates compared with the E. faecium isolates (55.7\%). The MIC of garlic's aqueous extract for95 E. faecium isolates were as follows: 74 resistant samples (78\% , MIC $\geq 8), 6$ semi-susceptible samples (6.3\% , MIC $4-8 \mu \mathrm{g} / \mathrm{ml})$ and 15 susceptible samples $(15.8 \%, \mathrm{MIC} \leq 4 \mu \mathrm{g} / \mathrm{ml})$. The MIC amounts for the $25 \mathrm{E}$. faecium isolates included: 21 resistant samples $(84 \%, \mathrm{MIC} \geq 8)$, 1 semi- susceptible sample (4\% , MIC 4-8 $\mu \mathrm{g} / \mathrm{ml})$ and 2 susceptible samples $(8 \%$, MIC $\leq$ $4 \mu \mathrm{g} / \mathrm{ml}$. The results of disk diffusion and agar dilution were completely concordant which indicates higher resistance of E. faecium in comparison to E. faecalis. Garlic Aqueous extract's average diameter of growth inhibition zone in the studied Enterococci was measured as $16.8 \pm 1.8 \mathrm{~mm}$. The results of this study indicated reduced growth of MDR bacterial colonies in the presence of garlic's aqueous extract after incubation at $37{ }^{\circ} \mathrm{C}$ for 24 hours. The diameter of growth inhibition zone for any MDR specie was reported as $17.3 \pm 0.4 \mathrm{~mm}$.

Table 1- Distribution of Enterococcus strains against Vancomycin in terms of species

\begin{tabular}{lccc} 
Enterococcus strains & $\begin{array}{c}\text { VSE }^{*} \\
\text { Number }\end{array}$ & $\begin{array}{c}\text { VRE*tal } \\
\text { Number }\end{array}$ & Number $(\%)$ \\
\hline E.faecalis & 90 & 5 & $95(79)$ \\
E.faecium & $6(5)$ & 19 & $25(21)$ \\
Total & 96 & 24 & $120(100)$ \\
\hline
\end{tabular}

Table 2- antibiotic susceptibility testing of Enterococcal isolates

\begin{tabular}{|c|c|c|c|c|c|}
\hline Antibiotic & $\begin{array}{l}\text { Sensitive } \\
\text { (percent) }\end{array}$ & $\begin{array}{l}\text { Semi-Sen } \\
\text { (percent) }\end{array}$ & $\begin{array}{c}\text { Resistance } \\
\text { (percent) }\end{array}$ & Disc Difussion & $\begin{array}{c}\text { MIC } \\
(\mu \mathrm{g} / \mathrm{ml})\end{array}$ \\
\hline Erythromycin & 0.8 & 3.4 & 95.8 & 15 & $0.01-128>$ \\
\hline Tetracycline & 8.3 & 3.4 & 88.3 & 30 & $0.08-128>$ \\
\hline Ampicillin & 6.6 & 27.6 & 65.8 & 10 & $0.08-128>$ \\
\hline Gentamicin & 45.9 & 20.8 & 33.3 & 10 & 0.08-1024 \\
\hline Ciprofloxacin & 40 & 35 & 25 & 5 & 0.04-32 \\
\hline Ciprofloxacin & 80 & $\mathbf{0}$ & 20 & 30 & $0.02-256>$ \\
\hline Chloramphenicol & 86.6 & 6.7 & 6.7 & 15 & $0.02-256>$ \\
\hline
\end{tabular}




\section{DISCUSSION}

Entrococci are linked to one of the most important types of intestinal infections. Increased bacterial resistance against antibiotics highlighted the need for developing antibacterials to enhance infection control. Use of medicinal plants is one of the most commonly used methods of treatment and symptom control since ancient times. In this study, a total of 120 Enterococcal isolates were investigated. Various studies in Iran suggests that this bacterium is endemic in hospitals and has an important role in hospital infections $(11,12)$. In a study in Babol, the frequency of isolation for E. faecalis and $E$. faecium were reported as $63 \%$ and $33 \%$, respectively (13). Meanwhile, Hayes et al. reported $53.2 \%$ and $31.4 \%$ isolation for these species (14). In this study, 115 Enterococcal isolates $(98.8 \%$ of all isolates) were erythromycin-resistant. This level of resistance was in agreement with findings of Farokh and Oskoyi (15), but significantly higher than the level reported by Dadfarma et al. in Hamedan (68\%)(13). In a similar study in India, $85 \%$ of the Enterococcal isolates were erythromycin-resistant (16) and in a study in Italy except the E. faecalis isolates, $87 \%$ of E. faecium isolates were also resistant to this antibiotic (17). Erythromycin is considered as an alternative for penicillin in allergic patients and is used in infection prophylaxis such as subacute bacterial endocarditis. The level of tetracycline resistance in this study was $88.3 \%$, while Oskoyi and Farokh reported 21\% resistance for this antibiotic in Tehran (15). This increased resistance may be associated with ease of access and consumption of this antibiotic in the country. In this regard, Sing's investigation in India showed 40\% resistance to this antibiotic in Enterococci (18). In another study in India, the resistance to aminoglycosides has been reported as 37\% (19). Among the 120 Enterococcal isolates in this study, 30 isolates were ciprofloxacinresistant (25\%), while the level of resistance to this antibiotic was higher in E. faecium compared to E. faecalis ( $80 \%$ vs. $10.5 \%$ ). Moreover, 20.9\% of all Enterococci were resistant to vancomycin (MIC $\geq 8 \mu \mathrm{g} / \mathrm{ml}$ ). There are very limited studies on vancomycin resistance in Enterococci strains with often divergent results. While Asgarian et al. reported the prevalence of vancomycin resistant Enterococci in hospitalized patients in city of Shiraz as 14\% (20), a study in India in 2003 reported only $1 \%$ vancomycin resistance in these bacteria (16). Nevertheless, recent studies have reported $80.2 \%$ resistance to this antibiotic in India (18). In the present study, the level of resistance to other antibiotics was also higher among vancomycin resistant isolates. The study of AslaniMehr et al. investigated the MIC of 165 isolates using the agar dilution method and their results showed that 7 isolates (4.2\%) were susceptible to erythromycin $(\mathrm{MIC} \leq 0 / 5 \mu \mathrm{g} / \mathrm{ml}), 11$ isolates $(6 / 6 \%)$ were intermediate (MIC $1-4 \mu \mathrm{g} / \mathrm{ml}$ ) and 147 isolates $(89 \%)$ were resistant to erythromycin (MIC $\geq 8 \mu \mathrm{g} / \mathrm{ml}$ ). Furthermore, the results of the disk diffusion and agar dilution methods in the mentioned study were completely concordant. Among 23 E. faecium isolates, $21(91.3 \%)$ were resistant to erythromycin which indicates higher antibiotic resistance in this specie compared to E. faecalis. Of 165 enterococci isolates, 18 (10.9 \%) had MIC of $<128 \mu \mathrm{g} / \mathrm{ml}$ and 147 isolates $(89 \%)$ had MIC of $>128 \mu \mathrm{g} / \mathrm{ml}$. MIC50 and MIC90 values of E. faecalis and E. faecium were higher than $128 \mu \mathrm{g} / \mathrm{ml}$ (20). In a study in Shiraz, all vancomycin-resistant enterococci isolates were also resistant to ampicillin, penicillin and gentamicin (21). According to the results of the present study, the average diameter of inhibition zone of garlic's aqueous extract in the tested Enterococci was $16.8 \pm 1.8 \mathrm{~mm}$. Lwalokun et al. reported the average diameter of the inhibition zone of this extract in Grampositive bacteria, between 20.2 to $21.8 \mathrm{~mm}$ (2). This difference may be due to diversity of tested garlic extract concentrations and the method of antibacterial properties assessment, since the present study used the disk diffusion method, while the other study had used the well diffusion method. According to the same study, the diameter of growth inhibition zone increased after 24 hours, thus the antibacterial effects of garlic's aqueous extract were reported as dose- and time-dependent (2). On the other hand, longer periods may reduce the concentration of garlic's active constituents. In this regard, Lemar et al. reported that fresh garlic extract has higher effects on morphology and growth inhibition of Candida 
compared to its old extract (22). Ruddock et al. study compared the antibacterial activity of natural garlic health products and fresh garlic extract against Neisseria gonorrhoeae, Staphylococcus aureus and Enterococcus faecalis using the microdilution method. Garlic extract of health products had $47 \%$ inhibitory effect on $N$. gonorrhoeae, and only $16 \%$ antibacterial effect against S. aureus and E. faecalis. In general, products containing garlic compounds have higher antimicrobial activity in comparison with fresh garlic extract (23). The results of the present study confirm the importance of genetic resistance patterns of Enterococci and continuous monitoring of this resistance in the region. Moreover, the results indicate the effect of garlic extract on elimination of Enterococcus strains and antibiotic resistant strains in particular. However, further studies are recommended on other Enterococci strains before its clinical application in pre-clinical

\section{REFERENCES}

1. Haciseferogullari H, Ozcan M, Demir F, Calisir S. Some nutritional and technological propertuies of garlic (Allium sativum L.). J food Eng. 2005; 68(4): 463-9.

2. Iwalokun BA, Ogunledun A, Ogbolu DO, Bamiro SB, Jimi-Omojola J. In vitro antimicrobial properties of garlic extract against multidrug resistant bacteria and candida species from Nigeria. J Med food. 2004; 7(3): 327-333.

3. Sivam GP. Protection against Helicobacter pylori and other bacterial infections by garlic. J Nutr 2001; 131(3s): $1106 \mathrm{~s}-1108 \mathrm{~S}$.

4. Hosseini-Jazani N, Shahabi S, Abidi-Ali A, Sahar Z, Ali Daei N. In vitro antibacterial activity of garlic against isolates of Acinetobacter sp. J Biol Sci. 2007; 7(5): 819-822.

5. Biavasco F, Folia G, paoletti C, Zandri G, Magi G, Guaglinone E, et al. VanA-type Entrerococci from humans, animals, and food: species distribution, population structure, Tn1546 typing and location, and virulence determinants. Appl Environ Microbial 2007; 73(10):3307-19.

6. Ako-Nai AK, Ikem IC, Aziba A, Ajaie AA, Onipede OA. Bacteriological examination of chronic osteomyelitis cases in Ile-Ife, South Western Nigeria. Af J Clin Exp Microbial. 2003; 4(2): 41-51.

7. Prakash JV, Richardson D, Williams R, Vyas VH. In vitro study of antimicrobial effects of allicin on vancomycin resistant enterococci. Abstracts of The Interscience Conference on Antimicrobial Agents \& Chemotherapy. 41: 201.

8. Bakeri IM, Douglas CW. Inhibitory effect of garlic extract on oral bacteria. Arch Oral Biol. 2005; 50(7): 645-51. settings for the treatment of Enterococcal infections. Ishimaru et al. measured the in vivo antimicrobial activity of some medicinal plants in vivo and reported high antibacterial activity of ginger and garlic extract against Gram-negative bacteria. The MIC value for garlic in the mentioned study was found as $4.48 \mathrm{mg} / \mathrm{ml}$ for Enterococcus strains. Grampositive bacteria were more susceptible to extracts of cloves and Indian hyacinth (24).

\section{CONCLUSION}

The present study indicates the clear antienterococcal effect of aqueous extract of garlic and confirms the use of garlic in treatments by medicinal plants.

\section{ACKNOWLEDGEMENT}

The author would like to thank all the physicians and faculty members of Babol University of Medical Sciences who helped us throughout this study. All costs of this study were provided by the authors.

\section{CONFLICT OF INTEREST}

Therer are no conflicts of interest.

9. Manero A, Blanch AR. Identification of Enterococcus spp. with a biochemical key. Appl Environ Microbiol. 1999; 65(10): 4425-30.

10. Clinical and Laboratory Standards Institute. Methods for dilution antimicrobial susceptibility tests for bacteria that grow aerobically. 2009; 26(2): M07A8.

11. Talebi M, Eshraghi SS, Pourshafi MR, Salari MH. Characterization of vancomycin resistant Enterococcus faecium. Iran J Publ Health 2007; 36(4): 20-5.

12. Feizabadi MM, Aliahmadi A, Mobasheri F, Asgharzadeh A, Asadi S, Etemadi G. Phenotypic characteristics and population genetics of Enterococcus faecalis cultured from patients in Tehran during 20002001. Can J Microbiol. 2003; 49(4): 654-9.

13. Dadfarma N, Oskoei M, Imani Fouladi A, Farokh P. [Study of aac(6')le-aph(2")la gene in clinical strain of enterococci] Persian. Sci J Hamedan Univ Med Sci. 2010; 17(3): 25-32.

14. Hayes JR, English LL, Carr LE, Wagner DD, Joseph SW. Multiple-antibiotic resistance of enterococcus spp. Isolated from commercial. Microbiol. 2004; 70(10): 6005-6011.

15. Oskoui M, Farrokh P. Distribution of insertion sequences associated with Tn1549 and clonal diversity of vancomycin-resistant enterococci isolated from patients in Tehran, Iran. IJM. 2010; 2(1): 15-22. [Persian]

16. Mathur P, Kapil A, Chandra R, Sharma P, Das B. Antimicrobial resistance in Enterococcus faecalis at a tertiary care centre of northern India J Med Res 2003; 118: 25-28. 
17. Busani L, Del Grosso M, Paladini C, Graziani C, Pantosti A, Biavasco F. Antimicrobial enterococciisolated in Italy from raw meat products, farm animals, and human infections. Int $\mathrm{J}$ Food Microbial 2004; 97(1): 17-22.

18. Singh BR. Prevalence of vancomycin resistance and multiple drug resistance in equids in north india. $\mathrm{J}$ Infect Dev Ctries. 2009; 3(7): 498-503.

19. Vergis EN, Hayden MK, Chow JW, Snydman DR, Zervos MJ, Linden PK, et al. Determinants of vancomycin resistance and mortality rates in enterococcal bacteremia: A prospective, multicenter study. Ann Intern Med 2001; 135(7): 484-92.

20. Askarian M, Afkhamzadeh AR, Monabbati A. Prevalence of intestinal colonization by vancomycinresistant enterococci in Shiraz Namazi Hospital. Sci J Kurdistan Univ Med Sci. 2006; 10(4): 35-41.[Persian]

21. Aslani mehr M, Peimani A, Darzi ramandi D, Naserpour farivar T. Frequency of erm A, B, C genes in
Erythromycin resistant Enterococci isolated from Clinical samples of inpatients of Teaching Hospitals in Qazvin \& Tehran. Medical J of Mashhad Univ. 57(4): 655-662.

22. Lemar KM, Turner MP, Lioyd D. Garlic (Allium sativum) as an anti-candida agent; Comparison of the efficacy of fresh garlic and freeze-extracts. J Appl Microbiol. 2002; 93(3): 398-405.

23. Ruddock PS, Liao M, Foster BC, Lawson L, Arnason TJ, Dillon JA. Garlic natural health products exhibit variable constituent levels and antimicrobial activity against Neisseria gonorrhoeae, Staphylococcus aureus and Enterococcus faecalis. Phytother Res. 2005; 19(4): 327-34.

24. Ushimaru PL, Nogueira da Silva MT, Claudio Di Stasi L, Barbosa L, Junior AF. Antibacterial activity of medicinal plant extracts.2007. Braz J Microbiol. 2007; 38(4): $\quad 717-719$. doi.org/10.1590/S151783822007000400024 